capítulo na história do ensino institucional - o de arquitetura.

A segunda parte de cada capítulo é dedicada ao ensino mais especificamente. A autora, para todo o período analisado, optou pela abordagem do estudo dos regulamentos e da organização das cadeiras e aulas, dos respectivos docentes e dos programas em currículos anuais dos cursos especiais de engenheiro-arquiteto e engenheiro civil, o que permitiu distinguir quais as disciplinas especificamente arquitetônicas, que a seu ver "definem (...) o ensino de arquitetura preconizado pela Politécnica nos diferentes momentos" (p.43). Partindo da composição das disciplinas do curso fundamental, pré-requisito para as duas especializaçôes em análise, onde se estabelece um repertório de noções sobre as ciências exatas, a autora disserta sobre a composição das disciplinas e aulas em cada ano do curso, buscando entender a formação dos arquitetos no período.

A terceira parte analisa os professores responsáveis pelas disciplinas especificamente arquitetônicas, apresentando uma biografia comentada de cada um deles e suas principais atuaçôes profissionais. Com a mesma metodologia, na quarta parte, Sylvia comenta a biografia dos diplomados e sua atuação profissional em São Paulo e em outros estados brasileiros, alguns com reconhecido destaque nacional.

Após recorrer todo esse percurso que a autora apresenta, fica claro o caminho trilhado na formação profissional do engenheiro-arquiteto até a divisão tanto profissional como de ensino que levam à formação específica do arquiteto. Apesar de sua leitura fácil e da sua forma didática de apresentação dos conteúdos, ao final do livro sentimos uma lacuna, a falta de uma amarração entre os três capítulos, alguns comentários finais, mas não há prejuízo para o entendimento global da obra. Por fim, podemos dizer que pela importância do seu conteúdo e pela lacuna que vem a preencher na historiografia, e também pela sua bela edição e a excelente qualidade da publicação, é um livro que não pode faltar na biblioteca daqueles que se interessam pelo ensino da arquitetura e pela formação profissional do arquiteto.

\section{BRASIL URBANO}

Edesio Fernandes

Marcio M. Valença (org.)

Rio de Janeiro: Mauad, 2004.

William E. N. Pereira

UFRN

Brasil urbano se constitui em uma coletânea de artigos de vários pesquisadores brasileiros e estrangeiros. Os artigos foram, inicialmente, publicados na revista inglesa GEOFORUM, no fim do ano de 2001. Posteriormente, foram traduzidos para o português e publicados pela editora Mauad. Composto de onze capítulos, Brasil urbano apresenta dois prefácios - um para a versão em inglês e outro para a brasileira -, escritos pelos organizadores da coletânea. O primeiro traz uma breve apresentação dos debates mais recentes e pertinentes sobre o processo de urbanização. O segundo faz a apresentação dos artigos componentes da coletânea.

O objetivo fundamental da coletânea é apresentar a urbanidade brasileira em sua grande diversidade de aspectos. Com esse objetivo, os organizadores juntaram onze artigos em forma de capítulos, de diversos e renomados pesquisadores, que analisam distintos aspectos da urbanização brasileira.

O primeiro capítulo do livro, de autoria de Ana Cristina Fernandes e Rovena Negreiros, é intitulado de "Desenvolvimento econômico, divisão de trabalho e mudanças na rede urbana brasileira: do desenvolvimentismo ao Plano Real". Nesse artigo, as autoras procuram reunir e discutir as principais transformações existentes entre a divisão social do trabalho e as formas dominantes das atividades produtivas. Com esse intuito, as pesquisadoras buscam, inicialmente, traçar um panorama do processo de urbanização do Brasil. Posteriormente, apresentam a rede urbana brasileira como fruto da integração nacional ocorrida nas últimas décadas. Em seguida, discutem a eficiência econômica e a fragmentação espacial nos anos 1990 no Brasil, ressaltando, especialmente, os efeitos das políticas neoliberais sobre o comércio exterior, a indústria e o emprego. Por fim, dis- 
cutem o perfil espacial dos investimentos públicos e privados recentes e as conseqüências espaciais das reformas ocorridas nos anos 1990.

Denominado de "Alguns aspectos da dinâmica recente da urbanização brasileira", o artigo de Marcelo Lopes de Souza procura discutir, no âmbito da metrópole periférica, a fragmentação do tecido sociopolítico-espacial. Na primeira parte, o autor trata do novo significado do "lumpemproleariado" urbano e o processo de auto-segregação das elites e de parte da classe média. $\mathrm{Na}$ segunda, discute conceitos como involução metropolitana, suburbanização ampliada e desmetropolização, sempre à luz da realidade brasileira.

No terceiro artigo, o sociólogo Ricardo Antunes procura, segundo suas próprias palavras, "apresentar as principais mutações que vêm acontecendo no mundo do trabalho, no novo sindicalismo e nos movimentos sociais do Brasil recente...”. Evidentemente, o autor entende que essas mutações são decorrências das transformações ocorridas no capitalismo contemporâneo e atingem, principalmente, as indústrias de base taylorista e fordista. No processo de integração à chamada mundialização, os paises latino-americanos participam destruindo-se socialmente; ou seja, para entrar no "trem" da mundialização, ampliase indescritivelmente a indigência social via aumento do desemprego, rebaixamento dos salários e precarização dos postos de trabalhos. No Brasil esse processo é plenamente percebido quando se olham o elevado índice de desemprego e o de desigualdade socioeconômica.

Andrés Rodriguez-Pose, John Tomaney e Jeroen Klink contribuíram para a coletânea com o artigo "Empoderamento local através de reestruturação econômica no Brasil: o caso da região do Grande ABC”. Partindo de um estudo de caso no $A B C$ paulista, os autores procuram mostrar que é o processo de reestruturação produtiva o principal responsável pela maior atividade de governos locais e regionais no Brasil. Segundo os autores, são as ameaças e as oportunidades criadas pela reestruturação produtiva que impulsionam os governos locais a reagirem aproveitando as oportunidades e afastando as ameaças desse processo ao "way of life" local.
"Exclusão territorial e violência: o caso de São Paulo, Brasil" é o titulo do artigo apresentado por Raquel Rolnik. Nesse artigo, a autora procura demonstrar a correlação existente entre o grau de exclusão territorial e o nível de violência. Ao explorar o nexo existente entre a violência urbana e a urbanização de risco, a autora busca propostas de políticas urbanas que possam enfrentar a exclusão territorial.

O capítulo seis traz o artigo de Flávio Antônio Miranda de Souza sobre os assentamentos informais. Estruturado a partir de um estudo de caso, o artigo "O futuro dos assentamentos informais: liçôes a partir da legalização de terras urbanas disputadas em Recife" combate a proposição amplamente aceita de que o direito de propriedade auxiliaria os segmentos mais pobres a melhorar suas condiçõos habitacionais. Constata o autor em seu estudo que existe uma relação entre a percepção da posse da terra, a consolidação dos assentamentos e as melhorias habitacionais. Essa relação resguarda um nível de sutileza muito maior do que o nível convencionalmente advogado pela escola dos direitos de propriedade.

A cidade de Belém do Pará é estudada no capitulo sétimo. José Júlio Lima discute a "Segregação socioespacial e forma urbana: Belém no final dos anos 90". O autor estrutura seu artigo em quatro partes. $\mathrm{Na}$ primeira, procura explicar os conceitos de forma urbana e segregação socioespacial. Na segunda, apresenta uma síntese dos aspectos contextuais da formação da estrutura urbana de Belém. Explica os métodos de análise na terceira parte, e fecha o artigo com a discussão sobre os resultados do estudo. Segundo o autor, os estudos da forma urbana são insuficientes para uma compreensão do processo de segregação. É necessário considerar as circunstâncias políticas que envolvem o processo de constituição da estrutura urbana. $\mathrm{O}$ resultado do estudo demonstra que a localização, per se, não explica a diferenciação socioeconômica, e que a distribuição dos valores se constitui em uma evidencia de que a segregação é afetada pela forma urbana, desde que outras variáveis sejam consideradas.

O Rio de Janeiro é foco de estudo dos capítulos oito, nove e dez. No primeiro dos três capí- 
tulos encontramos o estudo de Cláudio Acioli Jr. sobre a revitalização urbana do Rio de Janeiro. Denominado "Revisitando a revitalização urbana no Rio de Janeiro: do projeto urbano à gestão urbana", o artigo apresenta as estratégias de desenvolvimento urbano implementadas pela prefeitura dessa cidade nos anos 1990. Acioly Jr. destaca que os resultados do plano estratégico, do programa "Favela Bairro" e do programa de revitalização urbana possibilitaram melhorias consideráveis para os moradores das áreas atingidas por esses programas. Segundo esse autor, esses planos e programas se constituem em ações de caráter inovador, implementados pela prefeitura, com a participação da comunidade, que resultaram em significativas melhorias na gestão urbana do Rio de Janeiro.

Jorge Fiori, Elizabeth Riley e Ronaldo Ramirez apresentam o estudo "Melhoria física e integração social no Rio de Janeiro: o caso do Favela Bairro". Nele, buscam expor um marco analítico e propositivo, como também expõem sucintamente a política de habitação e favelas no Rio de Janeiro. O foco do estudo é o programa "Favela Bairro", desde sua concepção, implementação e revisão nos últimos anos. Os autores procuram mostrar os aspectos positivos e negativos, apresentando as dificuldades e os avanços sociais proporcionados por esse programa.

O terceiro artigo sobre o Rio de Janeiro, de autoria de Luciana L. Martins e Mauricio A. Abreu, discute os rebatimentos urbanísticos provocados pela chegada da corte portuguesa ao Brasil em 1808. Sob o título "Paradoxos da modernidade: o Rio de Janeiro no período joanino, 1808-1821", encontramos uma rica discussão sobre o significado e os impactos urbanos da chegada da corte portuguesa ao Brasil. Os autores questionam os rótulos de "pré-moderna" e "fechada" da sociedade brasileira no inicio do século XIX. Demonstram que o período joanino inaugurou a modernidade no Brasil, mas não se constituiu em uma modernidade pura, racional e iluminada. Pelo contrario, constituiu-se sim em uma modernidade diferente, caracterizada por um mistura entre escravismo e capitalismo, elementos de reação e de progresso.
O último capítulo da coletânea, de Stefania Abakerli, é sobre sustentabilidade. Fruto de uma pesquisa nos Lençóis Maranhenses, o artigo "Sustentabilidade em discurso e prática: implicações das políticas de desenvolvimento e de conservação em regiões biodiversificadas no Brasil" examina, inicialmente, o contexto sob o qual foi criado o modelo de áreas naturais protegidas, para, em seguida, analisar as implicações e as dimensões do poder implícitas no modelo. Posteriormente, o artigo indaga o processo pelo qual ocorre o estabelecimento das primeiras unidades de conservação no Brasil e, por fim, estuda os diversos interesses e relaçôes de poder que influenciaram a consolidação do Parque Nacional dos Lençóis Maranhenses.

Sabe-se que a dificuldade de produzir uma coletânea da envergadura de Brasil urbano é muito grande. Percebe-se que a coletânea se divide em duas grandes partes, embora não esteja explícito no livro. A primeira, com artigos mais gerais - os quatros primeiros artigos -; e a segunda, com casos mais particulares de algumas metrópoles - os demais artigos. Teria sido mais interessante se a coletânea trouxesse uma distribuição mais clara desses artigos, ou seja, que a coletânea se dividisse em duas partes, uma com artigos em geral e outra com estudos de caso das metrópoles.

Percebe-se, também, uma tendência para análise urbanística a partir do caso do Rio de Janeiro. $\mathrm{Na}$ coletânea encontramos três artigos sobre o Rio de Janeiro. Seria muito interessante se encontrássemos também artigos sobre as cidades de Fortaleza, Salvador, Belo Horizonte, Brasília, Porto Alegre e Manaus, permitindo assim que o leitor, após as leituras mais gerais, percebesse como se desenvolvem e quais os grandes problemas da urbanização das grandes metrópoles brasileiras, e conseqüentemente, do Brasil. Essa tendência voltada para o "Rio de Janeiro" favorece significativamente quem já vem estudando a cidade, mas deixa um vácuo para quem esperava que Brasil urbano apresentasse a urbanização brasileira em sua grande diversidade.

As demais metrópoles, não apresentadas na coletânea, têm especificidades muito particulares 
em seus respectivos processos de urbanização. Uma "viagem" pelas metrópoles brasileiras permitiria ao leitor uma visão generalizada da urbanização metropolitana nacional. Esse vácuo, quem sabe, pode ser sanado em uma nova coletânea Brasil urbano 2.

Brasil urbano é indicado para todos aqueles que querem conhecer e discutir as questôes básicas que afetam o processo de urbanização no Brasil. 